EPJ Web of Conferences 59, 04002 (2013)

DOI: $10.1051 /$ epjconf/20135904002

(C) Owned by the authors, published by EDP Sciences, 2013

\title{
Comparing neutron and X-ray images from NIF implosions
}

\author{
D.C. Wilson ${ }^{1}$, R.J. Aragonez', T.N. Archuleta ${ }^{1}$, D.P. Atkinson ${ }^{1}$, M.A. Barrios ${ }^{2}$, \\ S.H. Batha1 ${ }^{1}$, D.E. Bower ${ }^{2}$, D.K. Bradley ${ }^{2}$, R.A. Buckles ${ }^{4}$, D.D. Clark${ }^{1}$, \\ D.S. Clark ${ }^{2}$, D.J. Clark ${ }^{1}$, J.R. Cradick ${ }^{4}$, C.R. Danly ${ }^{1}$, R.D. Day ${ }^{1}$, J.M. Dzenitis ${ }^{2}$, \\ O.B. Drury², V.E. Fatherley ${ }^{1}$, B. Felker ${ }^{2}$, J.P. Finch ${ }^{1}$, D.N. Fittinghoff ${ }^{2}$, \\ M. Frank ${ }^{2}$, R.A. Gallegos ${ }^{1}$, F.P. Garcia ${ }^{1}$, S.M. Glenn², G.P. Grim¹, N. Guler ${ }^{1}$, \\ A.H. Hsu' ${ }^{1}$, N. Izumi ${ }^{2}$, S.A. Jaramillo ${ }^{1}$, O.S. Jones ${ }^{2}$, M.I. Kaufman ${ }^{5}$, \\ J.D. Kilkenny ${ }^{2}$, G.A. Kyrala1 ${ }^{1}$, S. Le Pape ${ }^{2}$, S.N. Liddick², E.N. Loomis', \\ S.S. Lutz ${ }^{4}$, T. Ma², A.J. Mackinnon², R.M. Malone ${ }^{5}$, D. Mares ${ }^{1}$, M.M. Marinak ${ }^{2}$, \\ D.D. Martinson ${ }^{1}$, P. McKenty ${ }^{3}$, N.S. Meezan², F.E. Merrill ${ }^{1}$, M.J. Moran², \\ G.L. Morgan ${ }^{1}$, C. Munson ${ }^{1}$, D.H. Munro ${ }^{2}$, T.J. Murphy ${ }^{1}$, J.A. Oertel ${ }^{1}$, \\ M.V. Patel ${ }^{2}$, P.J. Polk ${ }^{1}$, S. Regan ${ }^{3}$, G.P. Roberson ${ }^{2}$, D.W. Schmidt ${ }^{1}$, \\ S.M. Sepke ${ }^{2}$, B.K. Spears ${ }^{2}$, R. Tommasini ${ }^{2}$, R. Town ${ }^{2}$, A. Traille ${ }^{4}$, I.L. Tregillis ${ }^{1}$, \\ A.C. Valdez ${ }^{1}$, P.L. Volegov ${ }^{1}$, T.-S.F. Wang ${ }^{1}$, P. Weiss ${ }^{2}$, C.H. Wilde ${ }^{1}$ \\ and M.D. Wilke ${ }^{1}$
}

${ }^{1}$ Los Alamos National Laboratory, Los Alamos, New Mexico, US

${ }^{2}$ Lawrence Livermore National Laboratory, Livermore, California, USA

${ }^{3}$ Laboratory for Laser Energetics, U. of Rochester, Rochester, New York, USA

${ }^{4}$ National Security Technologies, Livermore Operations, Livermore, CA, USA

${ }^{5}$ National Security Technologies, Los Alamos Operations, Los Alamos, NM, USA

\begin{abstract}
Directly laser driven and X-radiation driven DT filled capsules differ in the relationship between neutron and X-ray images. Shot N110217, a directly driven DT-filled glass micro-balloon provided the first neutron images at the National Ignition Facility. As seen in implosions on the Omega laser, the neutron image can be enclosed inside time integrated $\mathrm{X}$-ray images. HYDRA simulations show the $\mathrm{X}$-ray image is dominated by emission from the hot glass shell while the neutron image arises from the DT fuel it encloses. In the absence of mix or jetting, X-ray images of a cryogenically layered THD fuel capsule should be dominated by emission from the hydrogen rather than the cooler plastic shell that is separated from the hot core by cold DT fuel. This cool, dense DT, invisible in X-ray emission, shows itself by scattering hot core neutrons. Germanium X-ray emission spectra and Ross pair filtered X-ray energy resolved images suggest that germanium doped plastic emits in the torus shaped hot spot, probably reducing the neutron yield.
\end{abstract}

Soon after the first laboratory neutron images of inertial confinement fusion (ICF) capsules were obtained [1], their physical interpretation has included comparison in size and shape with X-ray images [2]. Christensen et al. [3] carried out experiments on the Omega laser [4] with controlled asymmetry and compared the calculated and observed X-ray and neutron images. Wilson et al. [5] used these same implosions to study mix between the glass shell and DT fuel. In this paper we report the first comparison of neutron and X-ray images from both directly and radiation driven implosions on the National Ignition Facility Laser [6].

Fundamentally the X-ray and neutron emissions from an imploding ICF capsule have different sources. Neutron emission comes from regions of high D + T neutron production, i.e. high D and $\mathrm{T}$ ion

This is an Open Access article distributed under the terms of the Creative Commons Attribution License 2.0, which permits unrestricted use, distribution, and reproduction in any medium, provided the original work is properly cited. 


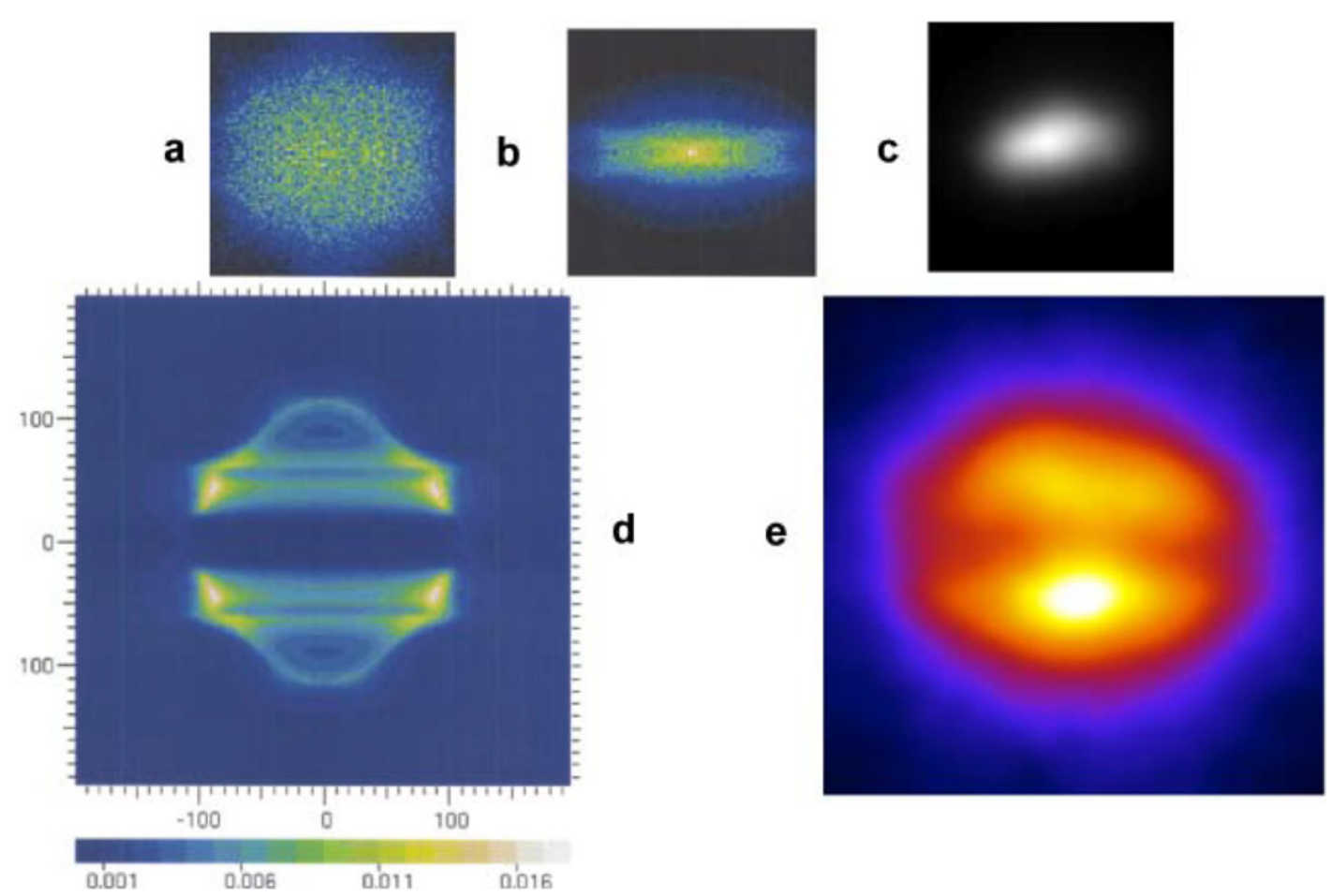

Figure 1. Calculated neutron images with nominal drive (a), with modified (b), observed (c), calculated nominal X-ray image (d), and observed (e). Large frames are $400 \mu \mathrm{m} \times 400 \mu \mathrm{m}$. Smaller frames are $200 \mu \mathrm{m} \times 200 \mu \mathrm{m}$.

densities, and high temperatures. During transit in the capsule, these neutrons may scatter, changing their direction and energy, but rarely are they absorbed. X-ray emission comes from free-free, bound-free and bound-bound emission in regions of high X-ray emissivity, which usually are also high electron density and high temperature. Plasma composition can be important. In particular emission from glass, plastic or germanium-doped plastic, can dominate the emission. In escaping the capsule X-rays are scattered and absorbed by intervening materials. Material composition, density, temperature differ between the two NIF capsule types we discuss here: directly laser driven glass shells containing DT gas, and radiation driven ignition capsules with germanium-doped plastic ablators and cryogenic layered fuels containing $\mathrm{D}, \mathrm{T}$, and $\mathrm{H}$.

Directly driven DT filled glass micro-balloons have been used at NIF to provide a source for neutron diagnostic development. Because the NIF beam directions do not uniformly illuminate a spherical target, polar direct drive beam pointing and focus [7] are used to approximate uniform illumination. The first image recorded [8] by the neutron imaging system [9] at NIF was on a $4.3 \mu \mathrm{m}$ thick $\mathrm{SiO} 2$ shell containing 7 atm of DT gas. The capsule was driven with a $2 \mathrm{~ns}$ long linear ramp laser pulse delivering $126 \mathrm{~kJ}$ and yielded $2 \mathrm{e}+14 \mathrm{DT}$ neutrons. The HYDRA radiation hydrodynamic code [10] performed two-dimensional calculations of the implosion. Simulated neutron images (figs. $1 \mathrm{a}$ and b), and an X-ray image (fig. $1 \mathrm{~d}$ ) are compared to observed neutron (fig 1c) and X-ray images (fig 1e). To help understand those images figure 2 shows the material, electron temperature, and density distributions at the time of peak neutron yield rate. The neutron image arises from the hot, low density DT inside the glass shell. The X-ray image is dominated by hot, dense, glass surrounding the DT. The calculated neutron image (1a) fits within the X-ray image (1d) as the observed neutron image 1c fits within the observed X-ray image (1e). Transferring $20 \%$ of the inner cone laser power to the outer laser cones produces the neutron image $1 \mathrm{~b}$, which is in better agreement with the observed image. 

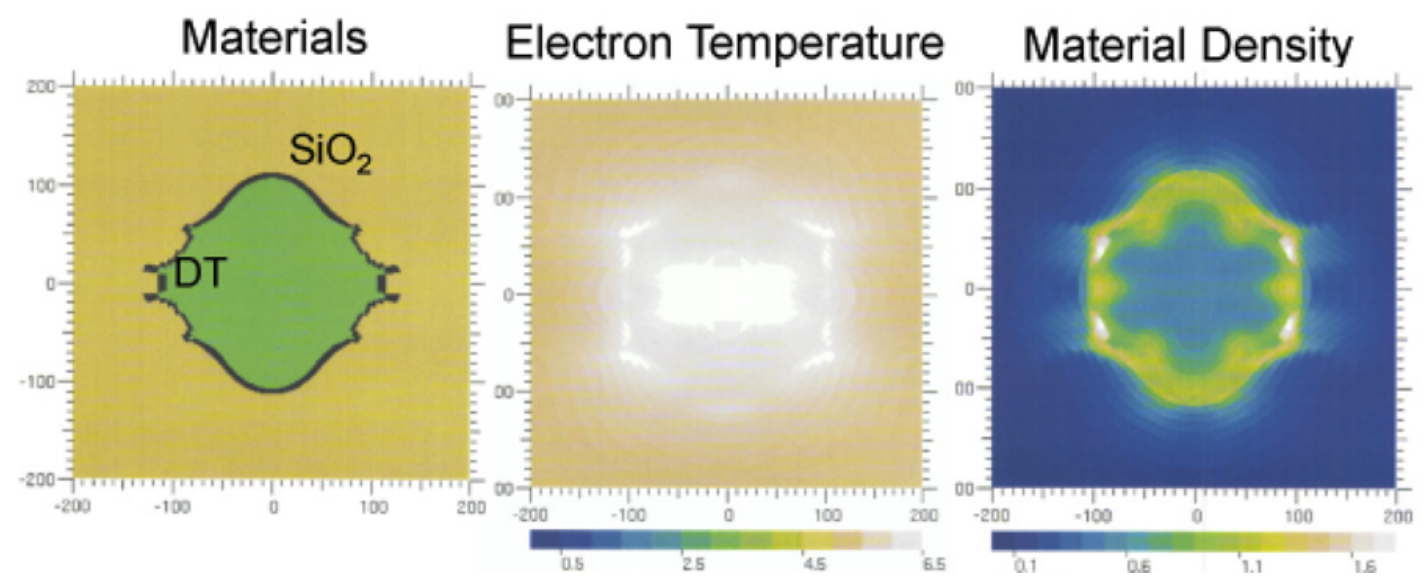

Figure 2. Material composition, electron temperature, and density at peak yield rate calculated for N110217. Each frame is $400 \mu \mathrm{m} \times 400 \mu \mathrm{m}$.
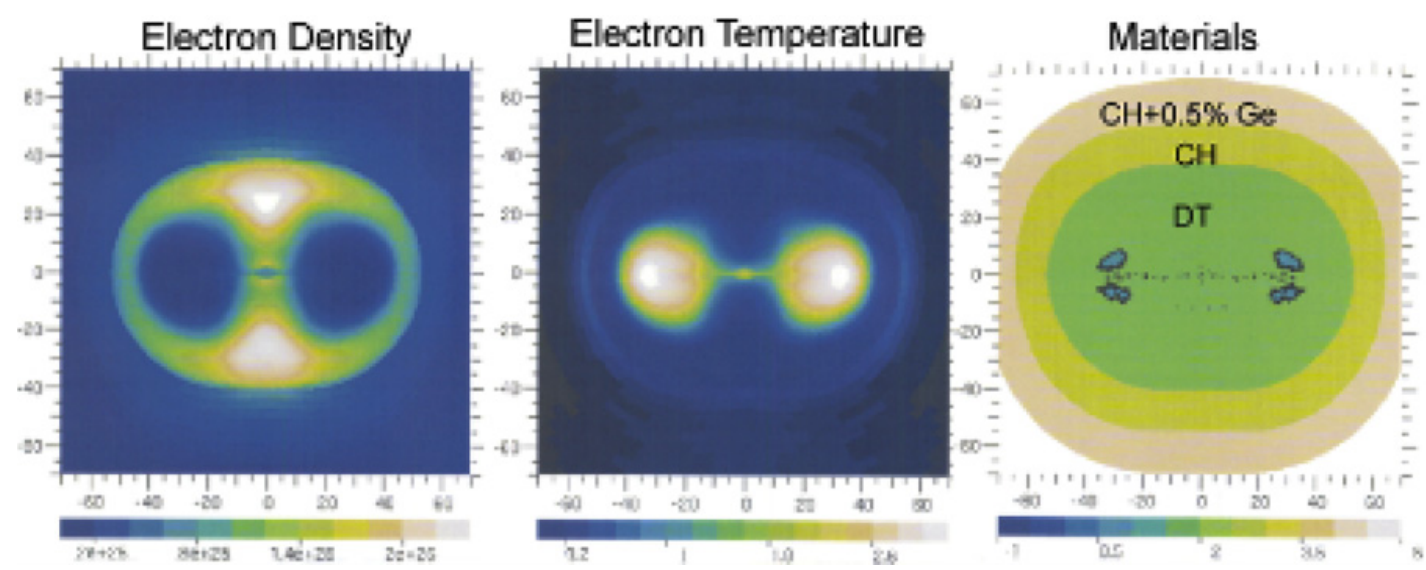

Figure 3. Electron Density, Temperature, and Material Composition at peak yield rate calculated for N110603.

The relation between X-ray and neutron images is different for a cryogenically layered THD capsule shown in figures 3 and 4 (NIF shot N110603). O. Jones [12] performed these calculations that match the observed time of peak yield rate (bangtime), down-scattered ratio (rho-r), and ion temperature. The calculated 13-15 MeV neutron and X-ray images (4a and 4c) are quite similar. Both arise from hot low-density hydrogen fuel. The experimental $13-15 \mathrm{MeV}$ neutron image and the equatorial Xray image (fig. $4 \mathrm{~g}$ ) differ. The polar X-ray image (fig. $4 \mathrm{~h}$ ) shows that the bright region on the left in fig. $4 \mathrm{~g}\left(\phi=78^{\circ}\right)$ should arise on the right of the observed neutron image (fig $4 \mathrm{e}, \phi=315^{\circ}$ ), where it appears less bright. Ross pair filtered time integrated X-ray images show that this bright feature is most prominent in 9-11 keV X-rays, suggesting it comes from germanium. A jet of doped plastic must have entered the low density burning fuel torus shown in figure $4 \mathrm{~d}$. Observed germanium emission lines indicate 2-35 ng of Ge doped plastic has reached an electron temperature of $2.2 \mathrm{keV}$ and density of $0.5-1 \mathrm{e}+25$ electrons $/ \mathrm{cm}^{3}$ [13]. Figure 3 shows that these are just the conditions in the hot torus. Perhaps this shell mixed into the fuel has reduced the DT yield from the calculated $3.2 \mathrm{e}+14$ to the observed $6.5 \mathrm{e}+13$. The similarity between the calculated and observed $10-12 \mathrm{MeV}$ (down-scattered) neutron images suggest the overall size of the compressed fuel is as calculated. 

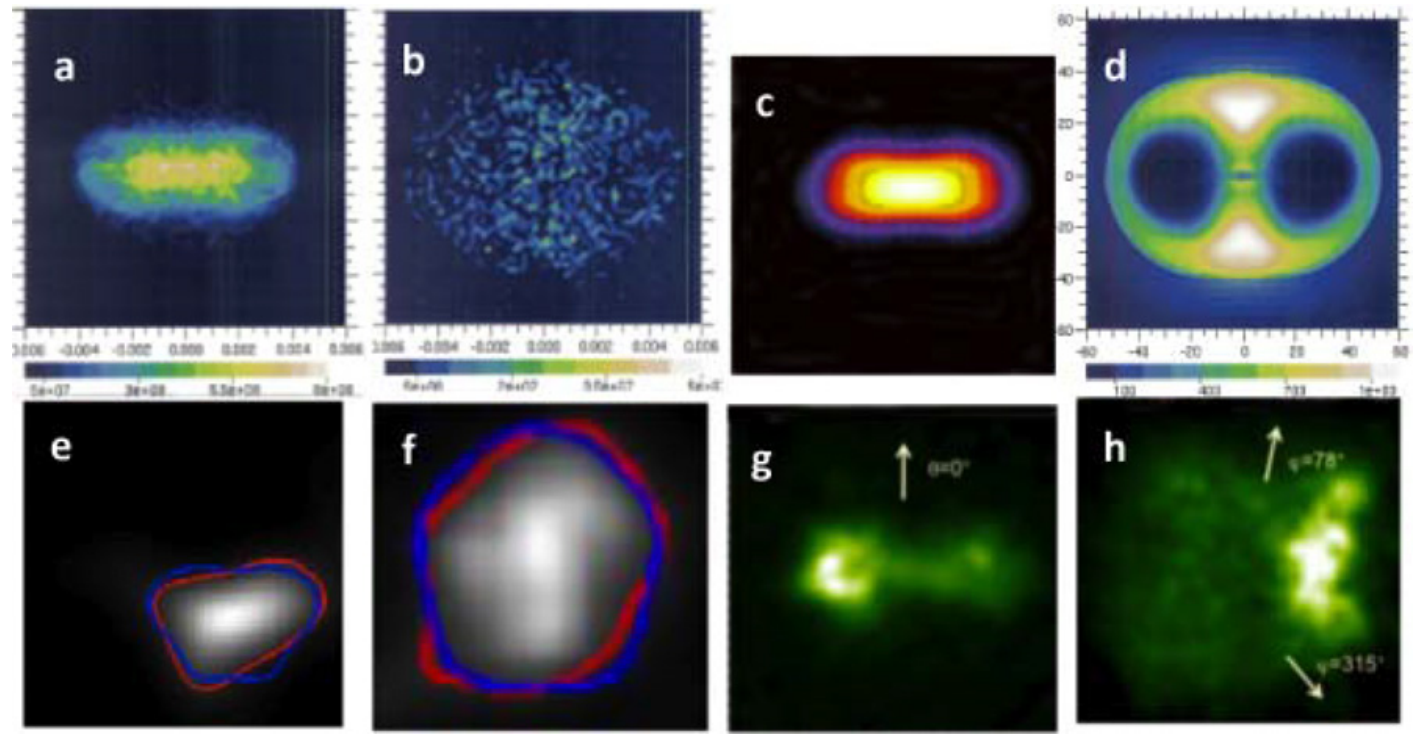

Figure 4. Calculated (a,b,c) and observed (e,f,g,h) images for N110603. Each frame is $120 \mu \mathrm{m} \times 120 \mu \mathrm{m}$. Figures $4 \mathrm{a}$ and e are from 13-15 MeV neutrons, Fig $4 \mathrm{~b}$ and from 10-12 MeV neutrons, Fig 4c and g, are equatorial views of X-rays above $6 \mathrm{keV}$, Fig $4 \mathrm{~h}$ is a polar view of X-rays, and Fig. $4 \mathrm{~d}$, the calculated densities at time of peak yield rate.

\section{References}

[1] D. Ress, R.A.Lerche, R.J. Ellis, S.M. Lane, K.A. Nugent, Science, 241, 956 (1988)

[2] L. Disdier, A. Rouyer, A. Fedotoff, J-L. Bourgade, F.J. Marshall, V.Yu. Glebov, C. Stoeckl, Rev. Sci. Instru., 74, 1832 (2003)

[3] C. Christensen, D C Wilson, C. W. Barnes, G. P. Grim, G. L. Morgan, M. D. Wilke, F. J. Marshall, V. Yu. Glebov, and C. Stoeck, Phys. Plasmas, 11, 2771 (2004)

[4] T. R. Boehly, D. L. Brown, R. S. Craxton, R. L. Keck, J. P. Knauer, J. H. Kelly, T. J. Kessler, S. A. Kumpan, S. J. Loucks, S. A. Letzring, F. J. Marshall, R. L. McCrory, S. F. B. Morse, W. Seka, J. M. Soures, C. P. Verdon, Opt. Commun. 133, 495 (1997)

[5] D.C. Wilson, C. W. Cranfill, C. Christensen, R.A. Forster, R. R. Peterson, N. M. Hoffman, G. D. Pollak, C. K. Li, F. H. Seguiin, J. A. Frenje, R. D Petrasso, P. W. McKenty, F. J. Marshall, V. Yu. Glebov, C. Stoeckl, G. J. Schmid, N. Izumi, P. Amendt, Phys. Plasmas, 11, 2723 (2004)

[6] J. A. Paisner, J. D. Boyes, S. A. Kumpan, W. H. Lowdermilk, and M. S. Sorem, Laser Focus World, 30, 75 (1994)

[7] S.Skupsky, J. A. Marozas, R.S. Craxton, R. Betti, T. J. B. Collins, J. A. Delettrez, V. N. Goncharov, P. W. McKenty, P. B. Radha, T. R. Boehly, J. P. Knauer, F. J. Marshall, D. R. Harding, J. D. Kilkenny, D. D. Meyerhoffer, T. C. Sangster, R. L. McCrory, Phys. Plasmas 11, 2763 (2004)

[8] G.P.Grim, et al., these Proceedings

[9] D.N.Fittinghoff, et al., these Proceedings

[10] M. M. Marinak, B. A. Remington, S. V. Weber, R. E. Tipton, S. W. Haan, K. S. Budil, O. L. Landen, J. D. Kilkenny, and R. Wallace, Phys. Rev. Lett. 75, 3677 (1995)

[11] S. Glenn, J. Koch, D.K.Bradley, N. Izumi, P. Bell, J. Holder, G. Stone, R. Prasad, A. MacKinnon, P. Springer, O. L. Landen, G. Kyrala, Rev. Sci. Instru 81, $10 \mathrm{E} 539$ (2010)

[12] O.S.Jones, et al., these Proceedings

[13] S.Regan, et al., presented to the IFSA 2011 conference 